\title{
Delaying investments in sensor technology: The rationality of dairy farmers' investment decisions illustrated within the framework of real options theory
}

\author{
C. J. Rutten, ${ }^{*}$ W. Steeneveld, ${ }^{* 1}$ A. G. J. M. Oude Lansink, $\dagger$ and H. Hogeveen* $\dagger$ \\ *Department of Farm Animal Health, Faculty of Veterinary Medicine, Utrecht University, Yalelaan 7, 3584 CL Utrecht, the Netherlands \\ †Chair group Business Economics, Wageningen University, Hollandseweg 1, 6706 KN Wageningen, the Netherlands
}

\begin{abstract}
The adoption rate of sensors on dairy farms varies widely. Whereas some sensors are hardly adopted, others are adopted by many farmers. A potential rational explanation for the difference in adoption may be the expected future technological progress in the sensor technology and expected future improved decision support possibilities. For some sensors not much progress can be expected because the technology has already made enormous progress in recent years, whereas for sensors that have only recently been introduced on the market, much progress can be expected. The adoption of sensors may thus be partly explained by uncertainty about the investment decision, in which uncertainty lays in the future performance of the sensors and uncertainty about whether improved informed decision support will become available. The overall aim was to offer a plausible example of why a sensor may not be adopted now. To explain this, the role of uncertainty about technological progress in the investment decision was illustrated for highly adopted sensors (automated estrus detection) and hardly adopted sensors (automated body condition score). This theoretical illustration uses the real options theory, which accounts for the role of uncertainty in the timing of investment decisions. A discrete event model, simulating a farm of 100 dairy cows, was developed to estimate the net present value (NPV) of investing now and investing in $5 \mathrm{yr}$ in both sensor systems. The results show that investing now in automated estrus detection resulted in a higher NPV than investing 5 yr from now, whereas for the automated body condition score postponing the investment resulted in a higher NPV compared with investing now. These results are in line with the observation that farmers postpone investments in sensors. Also, the current high adoption of automated estrus detection sensors can be explained because the NPV of investing
\end{abstract}

Received June 20, 2017.

Accepted March 25, 2018

${ }^{1}$ Corresponding author: w.steeneveld@uu.nl now is higher than the NPV of investing in 5 yr. The results confirm that uncertainty about future sensor performance and uncertainty about whether improved decision support will become available play a role in investment decisions.

Key words: dairy, sensor, investment, adoption, economics

\section{INTRODUCTION}

A sensor for cow management can be defined as a device that measures a physiological or behavioral condition (related to health or estrus) of an individual cow and enables automated, on-farm detection of changes in this condition that are related to a health event and require action on the part of the farmer (Rutten et al., 2013). In recent years, several sensors were developed, such as electrical conductivity sensors, SCC sensors, and color sensors for the detection of clinical mastitis (e.g., Hogeveen et al., 2010). Also, sensors were developed for measuring activity to detect estrus (e.g., Firk et al., 2002; O'Connell et al., 2010; Holman et al., 2011) and lameness (e.g., Pastell et al., 2009; Chapinal et al., 2010; Miekley et al., 2012). In addition, camera systems with automated image analysis were developed, such as the automated BCS (e.g., Bercovich et al., 2013; Spoliansky et al., 2016).

The adoption of sensors by farmers is in general low. Activity meters or pedometers are an exception to this general rule as they are adopted for detection of estrus (Borchers and Bewley, 2015; Steeneveld and Hogeveen, 2015). Around $20 \%$ of the Dutch farmers have activity meters or pedometers for detection of estrus (Steeneveld and Hogeveen, 2015). Other sensors are adopted much less frequently (e.g., weighing platforms) or hardly adopted yet (e.g., automated BCS; Steeneveld and Hogeveen, 2015). Earlier research by Steeneveld and Hogeveen (2015) showed that the main reasons for not investing (yet) for Dutch dairy farmers were having other investments priorities on the farm, uncertainty about the profitability of the investment, expecting poor integration of sensors with other farm 
systems and software, and waiting for improved versions of the sensors (Steeneveld and Hogeveen, 2015). The most important reasons for nonadoption of sensors by US dairy farmers were being unfamiliar with available technologies, expecting an undesirable cost-benefit ratio, and being provided with too much information without clear relevance for management (Russell and Bewley, 2013). These results indicate that economic considerations and waiting for improved versions, which provide better interpretable data or information, are important reasons for not adopting sensors on dairy farms.

Waiting for improved versions can be a rational choice for farmers and can explain why they do not yet adopt, particularly when one realizes that estrus detection performance improved considerably over the last 20 yr. In 1998, sensors for estrus detection were reported to have a sensitivity of $70 \%$ at a specificity of $60 \%$ (Frost et al., 1997), whereas Kamphuis et al. (2012) found a sensitivity between 62 and $75 \%$ at a specificity of $99 \%$. This means that sensors for estrus detection did undergo an enormous technological progress, and that less further improvement in detection performance can be expected. Hence, postponing the investment in estrus detection sensors is expected to have fewer advantages, and this may explain the currently high adoption rate. In contrast, sensors such as the automated BCS have been introduced much more recently and are still in the phase, as defined by Rutten et al. (2013), "of a technique measuring something about the cow." Body condition score is an assessment of the proportion of body fat a dairy cow possesses, and is associated with the incidence of ketosis (Roche et al., 2009). For pasture-based seasonal production systems, the importance of BCS is mentioned (Macdonald and Penno, 1998). For other systems, interpretable information with clear decision support on what to do with BCS is lacking in the scientific literature and not commonly known. Therefore, technological progress and more informed decision support, and thus a gain of postponing the investment, can be expected. The expected gain of postponing the investment may explain the currently low adoption rate.

Sensor technologies bear a great potential, but are generally characterized by low adoption rates on dairy farms. For sensor manufacturers it is important to realize that uncertainty about future technological progress may influence the adoption of sensors by farmers, and thus ultimately sales. The role of uncertainty about future technological progress in investment decisions can by structured by real options theory, which describes the problem structure, timing, linkage of decisions, and underlying uncertainties (Trigeorgis and Reuer, 2017). The overall aim of the current study was to offer a plausible example of why a sensor may not be adopted now. To explain this, the effects of uncertainty about future technological progress for sensors that are highly adopted (sensors for estrus detection) and are hardly adopted (automated BCS) were illustrated by using the real options theory. This illustration can help especially manufacturers to understand the effect of uncertainty of future technological progress on the adoption of sensors by dairy farmers.

\section{MATERIALS AND METHODS}

\section{Real Options Theory}

The real options theory is a method of option pricing from financial theory (Buhl et al., 2016). In corporate investment decisions and strategic management under uncertainty, real options theory can be used to clarify the problem structure (e.g., the different options, management decisions, and their timing), to appraise the options [i.e., estimating the net present value (NPV) of each option] and to plan the implementation (i.e., a strategic timeline that defines at which moment what option should be executed) (Trigeorgis and Reuer, 2017). Previously, the real options theory has been used to determine the timing of investment in information technology (IT) solutions. The real options theory was very well suited for this problem because the future developments in IT solutions are highly uncertain, and therefore timing of investment is complex (Buhl et al., 2016). Investing in sensors on dairy farms can be seen as a specific example of IT investment decisions. Also, the future technological progress is uncertain for sensors, and this makes timing of investment a difficult decision. Therefore, the real options theory was used to illustrate the effects of uncertainty about future technological progress in sensor systems on investment decisions of dairy farmers.

\section{Net Present Value}

In the real options approach, different investment options are compared quantitatively. In the current analysis the NPV was estimated for "investment now" and "postponed investment" (investment in $5 \mathrm{yr}$ ) for sensors for estrus detection and automated BCS. The NPV is the sum of discounted cash flows that are attributable to the investment and the costs of the initial investment. For the estimation of the NPV, the cash flow that was attributable to the investment in a sensor technology on a dairy farm was estimated with a simulation model. This cash flow in year $t\left(C F_{t}\right)$ was estimated as the difference in gross margin between a simulated average dairy herd with and without the 
defined sensor. The difference in the gross margin with and without the sensor technology in year $t$ consisted of the following components: the margin of produced milk (revenues of sold milk minus feed costs) $\left(M M_{t}\right)$, the margin of reproduction (sales price of a calf minus costs for calving management and insemination costs; $M R_{t}$ ), labor costs $\left(L C_{t}\right)$, treatment costs of diseases $\left(T C_{t}\right)$ and the margin of culling and replacement (slaughter value of a culled cow minus the purchase price of a replacement heifer; $M C_{t}$ ) (Equation [1]):

$$
C F_{t}=\left(M M_{t}+M R_{t}+L C_{t}+T C_{t}+M C_{t}\right) .
$$

A life time of $10 \mathrm{yr}$ was assumed for both the estrus sensor and the automated BCS. It was assumed that the investment was incurred and paid in year 0 and that revenues and costs of using the sensor system were incurred and paid in the 10 subsequent years. For each year the cash flow was discounted assuming a discount rate of $5 \%$. The discounted cash flows were summed up over the life time of the sensor to estimate the NPV. In case the farmer undertakes the investment in year $i=$ 0 , the NPV is

$$
N P V=-I N V+\sum_{t=1}^{10} \frac{C F_{t}}{(1+r)^{t}},
$$

whereas the NPV of the postponed investment (i.e., in yr 5) is

$$
N P V=-I N V_{5}+\sum_{t=6}^{15} \frac{C F_{t}}{(1+r)^{t}} .
$$

The cash flows of postponed investment were also discounted assuming a discount rate $(r)$ of $5 \%$. The NPV of "investment now" (Equation [2]) was compared with the NPV of the "postponed investment" (Equation [3]) to determine the optimal decision (i.e., the decision that yields the highest NPV).

\section{Simulation Model}

A simulation model, simulating a herd with 100 dairy cows, was developed. The dairy cow in the simulation model was assumed to have performance equal to the average in the Netherlands [i.e., a production level of $8,573 \mathrm{~kg} / 305 \mathrm{~d}$ (CRV, 2016)], a base conception rate of $50 \%$, starts her estrus cycle at 35 DIM, with an interval of $21 \mathrm{~d}$ and a gestation length of $280 \mathrm{~d}$ (Table 1). The simulation model was a deterministic discrete event model, which is described schematically in Figure 1. Inseminations were modeled over a lactation, and it was assumed that calvings and subsequent inseminations are distributed evenly over a calendar year. Milk production was modeled with an average lactation curve for a cow in her third parity. Daily milk yields were modeled with a Dijkstra lactation curve (Dijkstra et al., 1997) based on coefficients of Rutten et al. (2016).

Simulation of Fertility. Estrus is simulated as the occurrence of ovulation in 3-wk intervals starting at $10.5 \mathrm{~d}$ after the end of the voluntary waiting period (VWP). Subsequently, the occurrence of estrus, metritis, and early embryonic death were modeled. The methodology of Inchaisri et al. (2010) was used, in which the probability of insemination success was milk yield dependent.

The first step of the model was to determine the average DIM of first insemination. This DIM was determined from the assumed VWP of 84 DIM plus the average number of days to the first estrus after the end of the VWP. For simulation of estrus, it was assumed

Table 1. Input variables and their sources of origin for variables in the simulation model

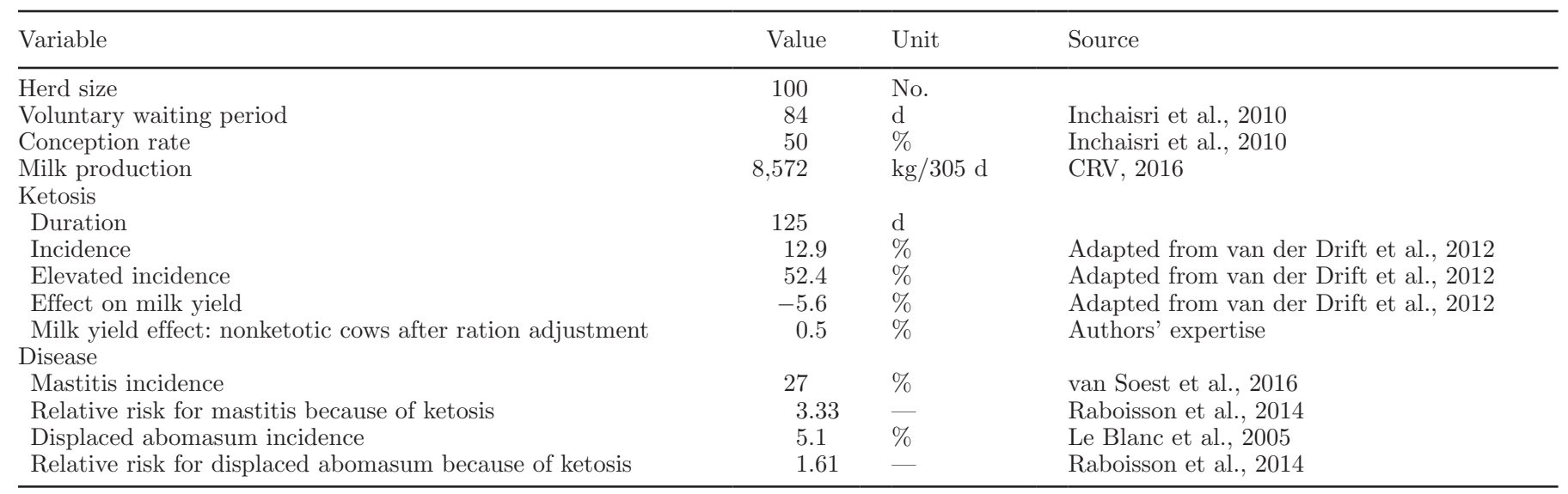




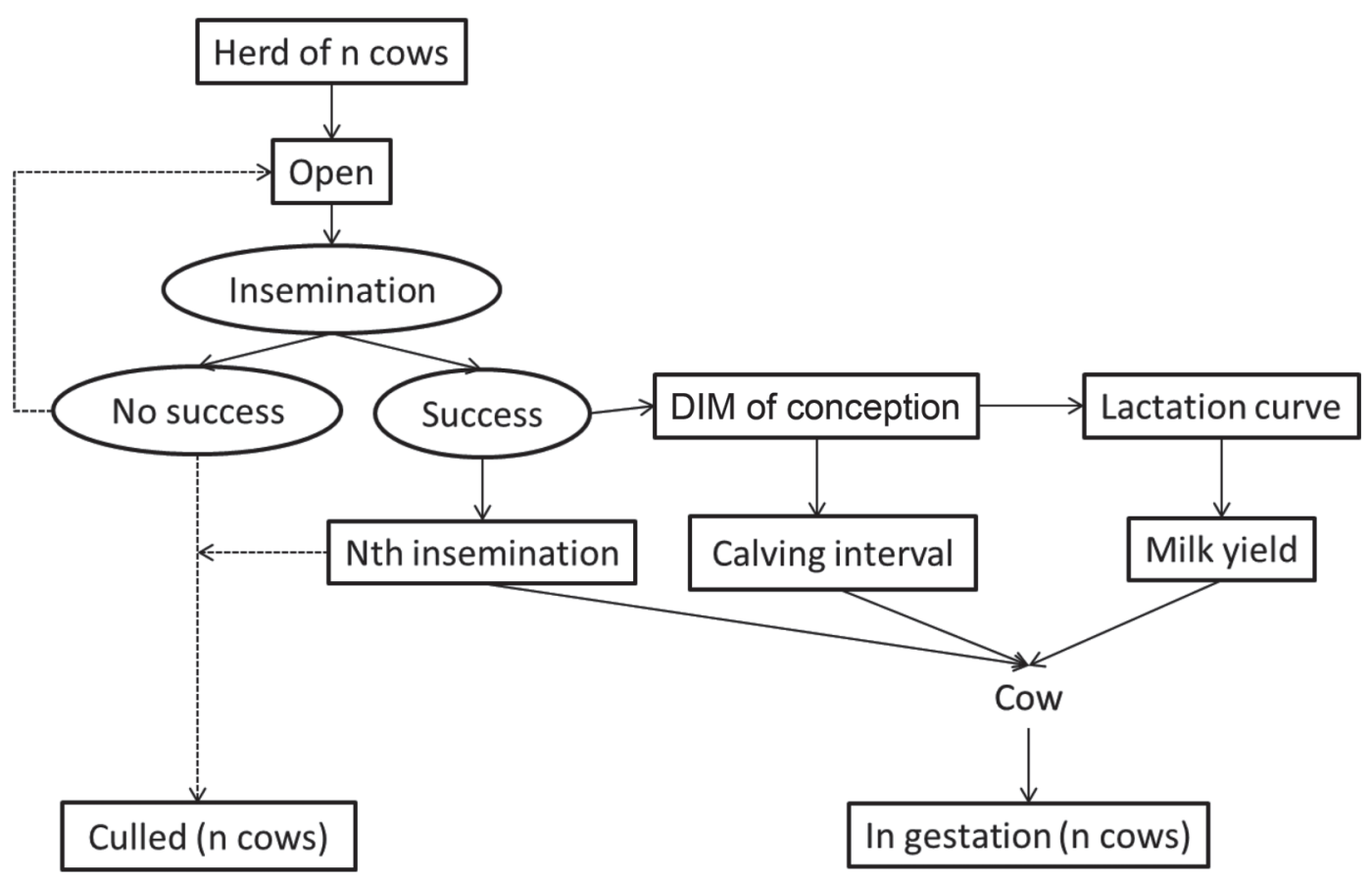

Figure 1. Schematic description of the simulation model that simulates reproduction and lactation of a herd of average dairy cows in a discrete event model.

that the estrus cycle length was 21 d. Each subsequent insemination is assumed to occur at, on average, $21 \mathrm{~d}$ after the previous one and that $5 \%$ of the cows would skip 1 full estrus cycle.

Based on the sensitivity of estrus detection, the probability that a cow being in estrus is detected was calculated per DIM according to the methodology of Steeneveld and Hogeveen (2012). This probability of detection was corrected for the relative DIM to the peak milk yield of the lactation.

The conception rate was estimated on each DIM for an average lactation. This included a base conception rate adjusted with a DIM-dependent factor, corrected for disease effects, the fertility difference between primi- and multiparous cows, and the occurrence of early embryonic death and metritis. The correction for disease effects assumed an incidence of $7 \%$ and an effect on conception rate of 38.5/47.4 (Inchaisri et al., 2010). The correction for fertility difference between primi- and multiparous cows assumed $32 \%$ primiparous cows in the herd with a conception rate that was 5 percentage points above the conception rate of multiparous cows (Inchaisri et al., 2010). The occurrence of early embryonic death and metritis was assumed to prohibit ovulation or conception. For both disorders, an incidence of $7 \%$ was assumed (Inchaisri et al., 2010), which resulted in $14 \%$ of the cows experiencing a disease that delays pregnancy. The overall conception rate of an average cow at each DIM was the product of the base conception rate, probability of estrus detection, and probability of conception. At each insemination the average overall conception rate was used to determine the average number of cows that conceived on the respective DIM.

Simulation of Hyperketonemia. The prevalence of hyperketonemia was reported to range from 0 to $80 \%$ with a mean of $11.2 \%$ (van der Drift et al., 2012). For the duration of disease it was assumed that hyperketonemia occurred once per lactation. With an average calving interval of $420 \mathrm{~d}$, the average duration of disease for hyperketonemia was $420 / 365.25=0.87 \mathrm{yr}$. For milk production, van der Drift et al. (2012) reported a decrease in milk production of $2 \mathrm{~kg} / \mathrm{d}$ at an average of $35.8 \mathrm{~kg} / \mathrm{d}$, which equals a decrease of $5.6 \%$. It was assumed that this decrease lasted for $125 \mathrm{~d}$. So, the decrease in milk production was assumed to last for 305 $\mathrm{d}-55$ DIM divided by 2 . This assumption was based upon the observation that at 60 DIM the prevalence of hyperketonemia decreases strongly and hyperketonemia is observed first at 5 DIM (van der Drift et al., 2012). The decrease in milk production was assumed to develop and cure gradually over time. Therefore, a gradual decrease over $5 \mathrm{~d}$ was assumed at the start of hyperketonemia and a gradual return to normal milk production over $15 \mathrm{~d}$ at the end of hyperketonemia. Furthermore, for hyperketonemia the conception rate 
was assumed to be $0.2 \%$ lower. Higher incidences of mastitis and displaced abomasum were assumed for cows with hyperketonemia (Table 1).

\section{Output Simulation Model}

The herd simulation model estimated average technical herd performance per year in terms of milk production, number of inseminations, calves born, and culled cows. To obtain these technical results, the herd simulation model estimated for each insemination ( 1 to 6 consecutive inseminations were assumed) how many cows had conceived. Subsequently, the length of the lactation was estimated under the assumption of a gestation length of $280 \mathrm{~d}$ and a dry-off period of $56 \mathrm{~d}$. For this lactation length, total milk yield per lactation was estimated based on the lactation curve of an average cow. The milk yield per lactation was converted to an average annual milk yield by correction with a year factor $(\mathrm{yf})=365.25 /$ lactation length. The total annual milk yield over all cows that did conceive was estimated and the average annual milk yield per cow was determined. Total annual herd milk yield was estimated by multiplying the average annual milk yield per cow with the herd size. This procedure was chosen because the developed deterministic discrete event model could not realistically simulate the complex nature of replacement decisions and therefore a realistic estimate of the average milk production of a culled cow and her replacing heifer was not considered feasible. Subsequently, the number of inseminations, calves, and culled cows were determined in the discrete event model and were each corrected to annual values with the year factor.

\section{Sensors and Their Performance}

The empirical illustration in this study focuses on a sensor that is already highly adopted (sensors for estrus detection) and a sensor that is currently hardly adopted (automated BCS). It was assumed that the sensors for estrus detection are mature developed sensors and do not make much technological progress anymore. This means that the gains due to technology improvement of "postponed investment" are only a bit higher than the gains of "investment now" (Figure 2A). For automated estrus detection it was assumed that for "investment now" the sensitivity would be $80 \%$ and the specificity 95\% (Hockey et al., 2010; Kamphuis et al., 2012; Rutten et al., 2014). Moreover, it was assumed that the integration of sensor outcomes with operational farm management is clear. For "postponed investment," a small technological improvement of the system was assumed (an increase of specificity to 99\%; Table 2). Both situations were compared with a farm where the farmer
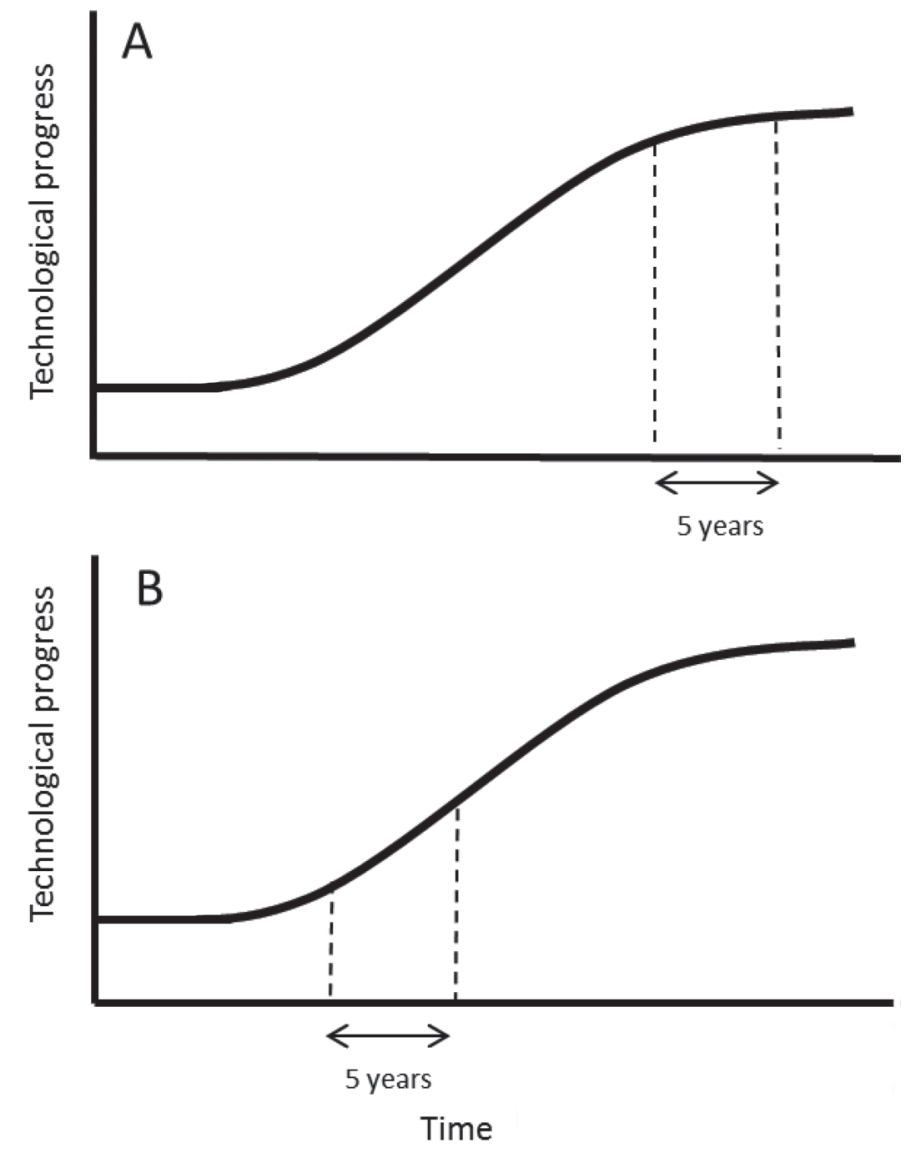

Figure 2. Graphical representation of the improved technological progress over time and its higher gains when the investment is postponed for 5 yr for estrus detection sensors (A) and for automated BCS (B).

applies visual estrus detection with a sensitivity of $50 \%$ and a specificity of $100 \%$, as assumed by Rutten et al. (2014).

It was assumed that automated BCS is a sensor for which much technological and managerial progress can be expected in 5 yr (Figure 2B). The performance of the automated BCS for both "investment now" and "postponed investment" is, however, unknown, and therefore assumptions based on expert knowledge were used. It was assumed that data from automated BCS can be used to adjust the ration when the number of cows in a negative energy balance increases (hence an increased incidence of hyperketonemia). When incidence of hyperketonemia increased, the intervention would be an adjustment of the feed ration. It was assumed that the feed ration on a dairy farm changes considerably 4 times per year. These changes are related to switching to the new silage made during last season (once for grass silage and once for maize silage), and the transition to pasture in spring and to the barn in autumn. It was assumed that using the automated 


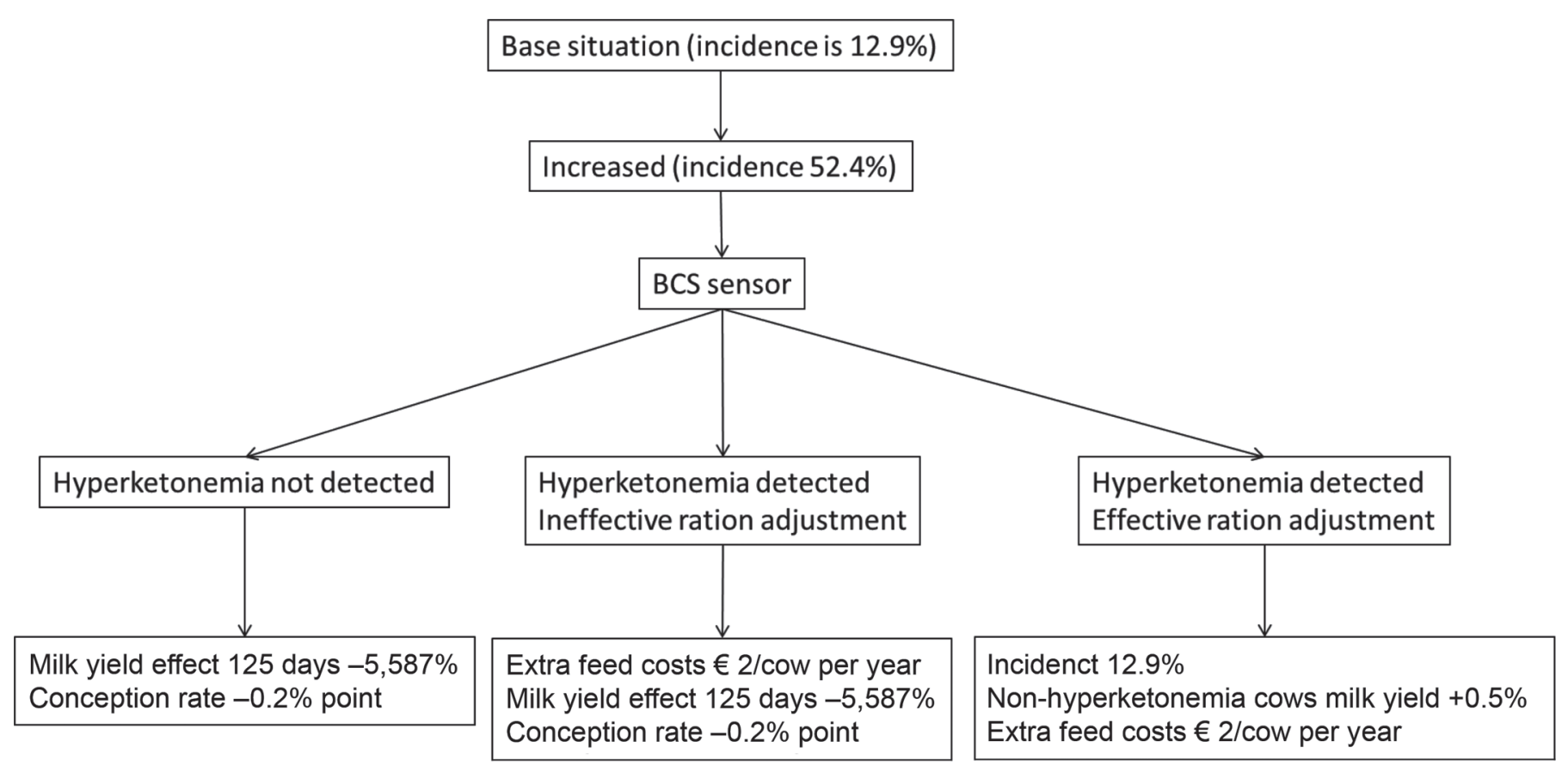

Figure 3. Schematic description of the feed ration adjustment on a dairy farm when the number of cows with hyperketonemia increases.

BCS can result in 3 situations, and these situations are described graphically in Figure 3 and input values are presented in Table 2. Either the automated BCS does not detect the increased number of cows with hyperketonemia (situation 1), the automated BCS does detect the increased number of cows with hyperketonemia but the measure taken is not effective (situation 2), or the automated BCS does detect the increased number of cows with hyperketonemia and the measure taken is effective (situation 3). For "investment now" it was assumed that each situation was equally likely to occur. For "postponed investment," it was assumed that BCS measurements become more reliable and that better integration with management is possible. Therefore, it was assumed that the likelihood of situation 1, 2, and 3 was 30, 20, and 50\%, respectively. Both "invest- ment now" and "postponed investment" were compared with a farm without automated BCS, where detection of hyperketonemia was $10 \%$ slower (based on expert opinion) than in the situation with automated BCS.

\section{Economic Estimations}

The technical results from the simulation model were used to estimate annual milk revenues, feed costs, insemination costs, revenues from calf sales, costs of calving management, revenues of slaughtered cows, and purchase costs of replacement heifers. Prices (Table 3) for inseminations, labor, slaughtered cows, and purchase of heifers were based on the assumptions of Rutten et al. (2014). Additionally, it was assumed that a farmer checks the alerts generated by the estrus detection sen-

Table 2. Input variables for the real options theory ${ }^{1}$

\begin{tabular}{|c|c|c|c|}
\hline Variable & $\begin{array}{c}\text { Value } \\
\text { (investment now) }\end{array}$ & $\begin{array}{c}\text { Value } \\
\text { (postpone investment) }\end{array}$ & Source \\
\hline $\begin{array}{l}\text { Estrus detection performance visual } \\
\text { Estrus detection performance with sensors }\end{array}$ & $\begin{array}{l}\text { SN: } 50 \%, \text { SP: } 100 \% \\
\text { SN: } 80 \%, \text { SP: } 95 \%\end{array}$ & $\begin{array}{l}\text { SN: } 50 \%, \text { SP: } 100 \% \\
\text { SN: } 80 \%, \text { SP: } 99 \%\end{array}$ & $\begin{array}{l}\text { Rutten et al., } 2014 \\
\text { Rutten et al., 2014; } \\
\text { Authors' expertise }\end{array}$ \\
\hline $\begin{array}{l}\text { Probabilities of situations for automated BCS } \\
\text { Hyperketonemia not detected and no ration measure } \\
\text { Hyperketonemia detected and no effective ration measure } \\
\text { Hyperketonemia detected and effective ration measure }\end{array}$ & $\begin{array}{l}0.3333 \\
0.3333 \\
0.3333\end{array}$ & $\begin{array}{l}0.30 \\
0.20 \\
0.50\end{array}$ & $\begin{array}{l}\text { Authors' expertise } \\
\text { Authors' expertise } \\
\text { Authors' expertise }\end{array}$ \\
\hline
\end{tabular}

${ }^{1}$ Detection performance was defined by the sensitivity (SN) and specificity (SP) of the detection algorithm of the sensor. 
Table 3. Economic input variables and their sources of origin for variables in the model

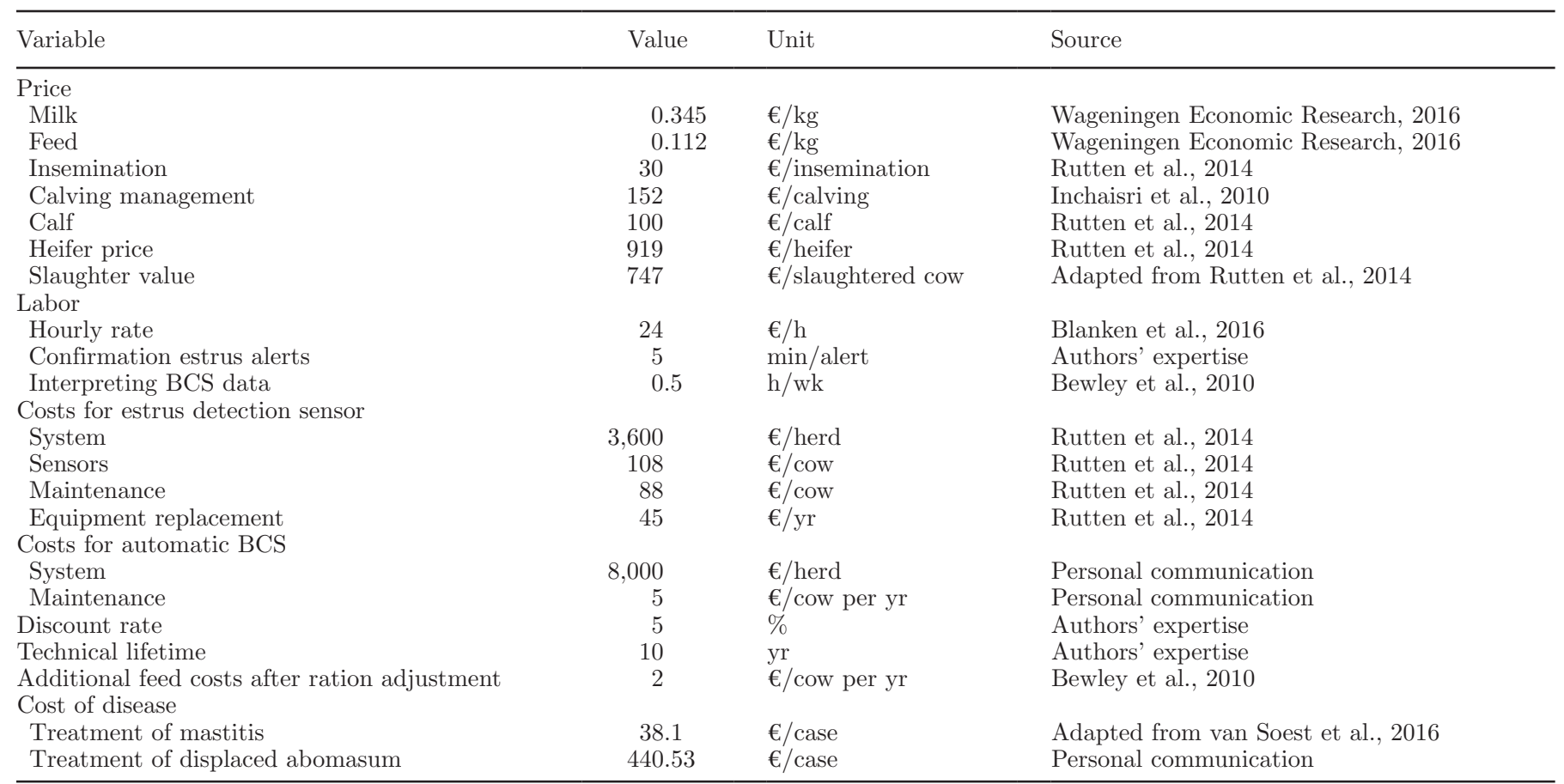

sor. Costs for checking were assumed to be €1.5 per alert (Rutten et al., 2014). For the automated BCS it was assumed that the farmer spends half an hour per week on interpreting BCS data.

For hyperketonemia, additional assumptions were made. It was assumed that adjustment of the feed ration as intervention for a high incidence of cows with hyperketonemia costs $€ 2$ per cow per year (adapted from Bewley et al., 2010). Cows with hyperketonemia have increased risk on mastitis and displaced abomasum. As the model already accounted for milk production losses due to hyperketonemia, it was assumed that no additional losses for mastitis and displaced abomasum occurred. The treatment costs (Table 3 ) for these 2 disorders were included in the economic estimations. Subsequently, annual farm gross margin was estimated as the difference between revenues and costs. The additional cash flow of applying a sensor was estimated by the difference in annual farm gross margin between the situation with a sensor and the situation without a sensor.

\section{Sensitivity Analysis}

In the sensitivity analysis, the effect of using different input values on the decision "investment now" or "postponed investment" were evaluated. For automated BCS the prevalence of hyperketonemia varies between farms (van der Drift et al., 2012). Therefore, situations with a high and low incidence of hyperketonemia were evaluated. The feed ration adjustment was based on the expertise of the authors because no studies were available that evaluated management improvements from the use of automated BCS. Therefore, the situation in which a ration adjustment without effect did not occur, for both "investment now" and "postponed investment," was evaluated. Also, sensors may become cheaper over time. Therefore, an additional sensitivity analysis was made to evaluate the situation in which both sensors became 10\% cheaper in 5 yr.

\section{RESULTS AND DISCUSSION}

Table 4 presents the results for automated estrus detection and automated BCS. The cash flows that are attributable to the sensor technology were positive for both "investment now" and "postponed investment." This indicates that both sensors are expected to improve herd management and produce a financial gain, excluding investment costs. For automated estrus detection, the results indicate that "investment now" results in a higher NPV $(€ 15,044)$ than postponing the investment $(€ 12,350)$. For the automated BCS, "postponed investment" results in a higher NPV (€3,139) compared with "investment now" $(-€ 1,015)$. These results imply that it is, from an economic point of view, rational for farmers to postpone the investment in BCS. The results are in line with the study of Steeneveld and Hogeveen 
(2015) who found that farmers did not (yet) invest in sensors because they are waiting for improved versions. The empirical illustration suggests it can be economically worthwhile to postpone investments in sensors for which there is much uncertainty, even if the NPV of an immediate investment is positive. Also, the current high adoption of automated estrus detection sensors (Steeneveld and Hogeveen, 2015) can be explained as rational, because the NPV of "investment now" is higher than the NPV of "postponed investment." So the expected improvements in performance do not outweigh the advantages of immediate investments. Overall, these results highlight that uncertainty about future sensor performance and uncertainty about whether improved informed decision support will become available play important roles in investment decisions.

Because of all the uncertainties and assumptions made, it cannot be concluded whether investment in automated BCS is profitable now or in the future. The current study merely illustrates that the uncertainties are there and that it is difficult to predict whether investment is profitable when so many uncertainties are involved. Dairy farmers who are interested in automated BCS will face the same issues as they cannot estimate what automated BCS will gain them and this may form a rational reason to postpone investment.

The current study was built upon the assumption that there is much uncertainty for the hardly adopted sensors. Automated BCS was chosen as an example because it is a sensor for which studies on the technical aspects of automatically measuring BCS have been published but evaluation of management and economic benefits have not. The same holds for sensors such as $\mathrm{pH}$ boluses or sensors for lameness detection (Rutten et al., 2013). Indeed, much uncertainty was present about the automated BCS because no scientific literature was available on the many input variables on hyperketonemia and the performance of the automated BCS, and therefore authors' expertise had to be used. First, hyperketonemia has a wide range of prevalence (van der Drift et al., 2012; McArt et al., 2015; Mostert et al., 2018), and the prevalence and severity of hyperketonemia are debated (Mostert et al., 2018). Second, it was assumed that the main benefit of the automated BCS was the ability to adjust the feed ration to the cows' needs and to prevent hyperketonemia problems. The magnitude of improvement in feed ration adjustments by using automated BCS was, however, unknown, and also the effectiveness of an adjustment in the feed ration is unknown. Because of this lack of knowledge, variables on hyperketonemia and on the effect of the automated BCS were included in the sensitivity analysis (Table 5). When the incidence of hyperketonemia
Table 4. Results of the investment analysis of a sensor for estrus detection and for automated BCS $^{1}$

\begin{tabular}{lrrr}
\hline Item & $\begin{array}{c}\text { Investment } \\
\text { now }\end{array}$ & $\begin{array}{c}\text { Postpone } \\
\text { investment }\end{array}$ & \multicolumn{1}{c}{$\Delta$} \\
\hline Automated estrus detection & & & \\
Investment $(€)$ & 14,400 & 14,400 & 0 \\
Additional cash flow $(€ / \mathrm{yr})$ & 3,813 & 3,906 & 93 \\
NPV $(€)$ A & 15,044 & 12,350 & $-2,694$ \\
Automated BCS & & & 0 \\
Investment $(€)$ & 8,000 & 8,000 & 650 \\
Additional cash flow $(€ / \mathrm{yr})$ & 905 & 1,555 & 6,154 \\
NPV $(€)$ & $-1,015$ & 3,139 & \\
\hline
\end{tabular}

${ }^{1}$ The additional cash flow is the financial gain that results from the use of a sensor. The net present value (NPV) for investment now was estimated over a 10-yr period, and the option to postpone investment was estimated over a 10 -yr period 5 yr from now.

was reduced to $25 \%$, the NPV of both "investment now" and "postponed investment" were negative, implying the investment should neither be undertaken now, nor $5 \mathrm{yr}$ from now. On the other hand, when the incidence of hyperketonemia was increased to $75 \%$ the NPV were positive though higher for the postponed decision. The finding of a higher NPV for the decision to postpone the investment implies that it is optimal for the farmer to select this option. Increasing the chance that hyperketonemia is detected and changing the effects of a feed ration adjustment influenced the NPV strongly. In the default scenario, postponing the investment in a BCS sensor had a €4,154 higher NPV than investing now, whereas with a better detection and a more effective ration measure postponing the investment had a €1,339 higher NPV. This implies that waiting for improved versions will be worthwhile. After a price decrease of $10 \%$ "investment now" was still more profitable for automated estrus detection and still not profitable for automated BCS. So, within the constraints of this illustrative study, a price decrease of $10 \%$ over 5 yr did not affect the timing of investment.

Besides the assumptions because of uncertainty for the hardly adopted sensors, other assumptions were also made. First, the simulation model was deterministic and therefore the stochastic nature of, for instance, hyperketonemia incidence, effect of ration adjustments, and detection of hyperketonemia were ignored. For these factors the input values will in practice vary between farms and will in reality be described by a probability distribution rather than by a fixed value. As these probability distributions were unknown, realistic stochastic modeling is difficult at this moment. For future research, stochastic modeling would be an interesting approach to further investigate the uncertainty and risk that is associated with investment decisions for sensor technology. Second, technological progress 
Table 5. Results of the sensitivity analysis of a sensor for estrus detection and for automated BCS

\begin{tabular}{|c|c|c|c|}
\hline Item & $\begin{array}{l}\text { Investment } \\
\text { now }\end{array}$ & $\begin{array}{l}\text { Postpone } \\
\text { investment }\end{array}$ & $\Delta$ \\
\hline \multicolumn{4}{|l|}{ Investment } \\
\hline Automated estrus detection & 14,400 & 14,400 & - \\
\hline Automated BCS & 8,000 & 8,000 & - \\
\hline \multicolumn{4}{|l|}{ Hyperketonemia incidence $25 \%$} \\
\hline Additional cash flow $(€ / y r)$ & 244 & 528 & 284 \\
\hline $\operatorname{NPV}(€)$ & $-6,114$ & $-3,075$ & 3,039 \\
\hline \multicolumn{4}{|l|}{ Hyperketonemia incidence $75 \%$} \\
\hline Additional cash flow $(€ /$ yr $)$ & 1,448 & 2,400 & 952 \\
\hline $\operatorname{NPV}(€)$ & 3,178 & 8,251 & 5,073 \\
\hline \multicolumn{4}{|c|}{ Probabilities of situations for automated $\mathrm{BCS}^{2}$} \\
\hline Additional cash flow $(€ /$ yr $)$ & 1,593 & 1,968 & 375 \\
\hline NPV $(€)$ & 4,298 & 5,637 & 1,339 \\
\hline \multicolumn{4}{|c|}{ Automated estrus detection ( $10 \%$ cheaper) } \\
\hline Investment $(€)$ & 14,400 & 12,960 & $-1,440$ \\
\hline Additional cash flow $(€ / y r)$ & 4,418 & 4,450 & \\
\hline $\operatorname{NPV}(€)$ & 15,044 & 13,112 & $-1,932$ \\
\hline \multicolumn{4}{|l|}{ Automated BCS (10\% cheaper) } \\
\hline Investment $(€)$ & 8,000 & 7,200 & -800 \\
\hline Additional cash flow $(€ /$ yr $)$ & 1,241 & 1,857 & 616 \\
\hline $\mathrm{NPV}(€)$ & $-1,015$ & 3,563 & 4,578 \\
\hline \multicolumn{4}{|c|}{$\begin{array}{l}{ }^{1} \text { The additional cash flow is the financial gain that results from the use of a sensor. The net present valu } \\
\text { (NPV) for investment now was estimated over a } 10 \text {-yr period, and the option to postpone investment wa } \\
\text { estimated over a } 10 \text {-yr period } 5 \text { yr from now. }\end{array}$} \\
\hline \multicolumn{4}{|c|}{$\begin{array}{l}{ }^{2} \text { Situations for automated BCS were hyperketonemia not detected and no ration measure, hyperketonemia d } \\
\text { tected and no effective ration measure, and hyperketonemia detected and effective ration measure. Probabiliti } \\
\text { for these situations for investment now were } 50,0 \text {, and } 50 \% \text {, respectively. Probabilities for these situations fo } \\
\text { postpone investment were } 40,0 \text {, and } 60 \% \text {. }\end{array}$} \\
\hline
\end{tabular}

was considered at 2 fixed (now and 5 yr from now) points in time. Therefore, technological progress in the period between these 2 time points was ignored. For some aspects of technological progress, this assumption is realistic. For instance, improved camera technology for the automated BCS will become available on the market at some moment, but the exact point in time on which the improvement becomes available is unknown. For other aspects of technological progress the assumption of 2 fixed moments in time is less realistic. For instance, improvement in detection algorithms may become available as part of a software update for a sensor system. So, technological progress over the 5 -yr period as assumed in the current study will develop in practice in a more constant way. When improvement is more constant, and with a positive NPV, investing now becomes the best option in more cases. For a full analysis, depreciation also needs to be taken into account as sensors wear out and new investments are necessary. Including depreciation is realistic for sensors and will influence the NPV of investing now in a positive way. It is also possible to analyze the NPV based on a cascade of options. In that case the result of investing now and investing in better technology in $10 \mathrm{yr}$ can be determined. Finally, the developed model was at the farm level, and no benefits of treatment of individual cows for ketosis were included. Including such benefits can increase the NPV of the BCS sensor.
The illustration in the current study helps to understand the effect of uncertainty of future technological progress on the adoption of sensors by dairy farmers and can explain why dairy farmers do not (yet) adopt sensors on their farms. Hence, the results suggest that uncertainty about future technological progress can be an important driver in the adoption of technology, an observation that was also made in previous studies (e.g., Purvis et al., 1995; Tozer, 2009). Previously, Kuehne et al. (2017) designed a tool to predict the adoption of new farming practices and concluded that benefit of the investment was one of the important indicators of adoption. Other important indicators were environmental impact and ease and convenience of the practice. The concepts and considerations presented in the current paper can be used for development of strategies to enhance adoption by farmers, and 3 examples of these strategies will be discussed. First, the results imply that a better insight into the economic benefits can enhance adoption of a sensor technology. A requirement for an economic analysis or investment analysis is that the performance and management benefits of a sensor are known and quantified. Previously, investment analyses for automated estrus detection have been conducted. Østergaard et al. (2005) estimated the breakeven point for investing in a system for online progesterone measurements, and Rutten et al. (2014) determined whether investing in automated estrus detection was profitable. 
Bewley et al. (2010) described models for analyzing an investment in sensor systems. This can help to inform farmers of the benefits of a sensor. Second, informed decision support, or advice relevant for operational management, as part of the sensor system is often lacking (Rutten et al., 2013). Estrus is an exception to this observation because the sensor produces a clear output (estrus alert), which has a clear management decision attached to it (breed or not). This difference in development, namely a clear link to and value for operational management, versus an unclear link and value, between estrus sensors and other sensors may well be a reason for the difference in adoption. Until now most research on sensors has focused on the detection of diseases or estrus and not on decision support possibilities based on the available data (Rutten et al., 2013). Therefore, offering decision support to farmers applying sensor technologies would be helpful in improving the value of sensor for operational management and would be a topic for future research. Finally, another way to reduce uncertainty can be offering support or demonstration of how the sensor can be used. Also, the guaranteed inclusion of (software) updates during the lifetime of the sensor can help to increase the benefits of investing now by facilitating access to future improvements. The importance of customer support has been highlighted before (Eastwood et al., 2012). Proper support could be used to help farmers to use sensor technology and gain more benefits from the sensor system and therefore reduce their uncertainty about the technology. Manufacturers of sensors can, therefore, consider the concepts presented in this study in their marketing.

\section{CONCLUSIONS}

This study illustrated that uncertainty about the benefits of a sensor, potential future improvement of sensor technology, and expected better management information from a sensor, form rational economic reasons to postpone investment in sensors. The uncertainties on the benefits of an automated BCS and the lack of knowledge on input values for the estimations were large and did prohibit conclusions on the profitability of such a system. The concepts and considerations presented in this paper can be used for further development of strategies to enhance adoption by farmers.

\section{ACKNOWLEDGMENTS}

This research was supported by NWO (Netherlands Organisation for Scientific Research, The Hague, the Netherlands).

\section{REFERENCES}

Bercovich, A., Y. Edan, V. Alchanatis, U. Moallem, Y. Parmet, H. Honig, E. Maltz, A. Antler, and I. Halachmi. 2013. Development of an automatic cow body condition scoring using body shape signature and Fourier descriptors. J. Dairy Sci. 96:8047-8059.

Bewley, J. M., M. D. Boehlje, A. W. Gray, H. Hogeveen, S. J. Kenyon, S. D. Eicher, and M. M. Schutz. 2010. Assessing the potential value for an automated dairy cattle body condition scoring system through stochastic simulation. Agr. Financ. Rev. 70:126-150.

Blanken, K., F. de Buisonje, A. Evers, W. Ouweltjes, H. van Schooten, J. Verkaik, I. Vermeij, and H. Wemmenhove. 2016. Livestock Research, Wageningen UR. Kwantitatieve Informatie Veehouderij 2016-2017. Wageningen, the Netherlands.

Borchers, M. R., and J. M. Bewley. 2015. An assessment of producer precision dairy farming technology use, prepurchase considerations, and usefulness. J. Dairy Sci. 98:4198-4205.

Buhl, H. U., B. S. Hackel, F. Probst, and J. Schosser. 2016. On the ex ante valuation of IT service investments. Bus. Inf. Syst. Eng. $58: 415-432$.

Chapinal, N., A. M. de Passille, J. Rushen, and S. Wagner. 2010. Automated methods for detecting lameness and measuring analgesia in dairy cattle. J. Dairy Sci. 93:2007-2013.

CRV. 2016. Annual report 2016. CRV (cattle breeding company), Arnhem, the Netherlands.

Dijkstra, J., J. France, M. S. Dhanoa, J. A. Maas, M. D. Hanigan, A. J. Rook, and D. E. Beever. 1997. A model to describe growth patterns of the mammary gland during pregnancy and lactation. J. Dairy Sci. 80:2340-2354.

Eastwood, C. R., D. F. Chapman, and M. S. Paine. 2012. Networks of practice for co-construction of agricultural decision support systems: Case studies of precision dairy farms in Australia. Agric. Syst. 108:10-18.

Firk, R., E. Stamer, W. Junge, and J. Krieter. 2002. Automation of oestrus detection in dairy cows: A review. Livest. Prod. Sci. $75: 219-232$.

Frost, A. R., C. P. Schofield, S. A. Beaulah, T. T. Mottram, J. A. Lines, and C. M. Wathes. 1997. A review of livestock monitoring and the need for integrated systems. Comput. Electron. Agric. $17: 139-159$

Hockey, C., J. M. Morton, S. T. Norman, and M. R. McGowan. 2010. Evaluation of a neck mounted 2-hourly activity meter system for detecting cows about to ovulate in two paddock-based Australian dairy herds. Reprod. Domest. Anim. 45:e107-e117.

Hogeveen, H., C. Kamphuis, W. Steeneveld, and H. Mollenhorst. 2010. Sensors and clinical mastitis-the quest for the perfect alert. Sensors (Basel) 10:7991-8009.

Holman, A., J. Thompson, J. E. Routly, J. Cameron, D. N. Jones, D. Grove-White, R. F. Smith, and H. Dobson. 2011. Comparison of oestrus detection methods in dairy cattle. Vet. Rec. 169:47.

Inchaisri, C., R. Jorritsma, P. Vos, G. C. van der Weijden, and H. Hogeveen. 2010. Economic consequences of reproductive performance in dairy cattle. Theriogenology 74:835-846.

Kamphuis, C., B. DelaRue, C. R. Burke, and J. Jago. 2012. Field evaluation of 2 collar-mounted activity meters for detecting cows in estrus on a large pasture-grazed dairy farm. J. Dairy Sci. 95:3045-3056.

Kuehne, G., R. Llewellyn, D. J. Pannell, R. Wilkinson, P. Dolling, J. Ouzman, and M. Ewing. 2017. Predicting farmer uptake of new agricultural practices: A tool for research, extension and policy. Agric. Syst. 156:115-125.

LeBlanc, S. J., K. E. Leslie, and T. F. Duffield. 2005. Metabolic predictors of displaced abomasum in dairy cattle. J. Dairy Sci. 88:159-170.

Macdonald, K. A., and J. W. Penno. 1998. Management decision rules to optimise milk solids production on dairy farms. New Zealand Society of Animal Production, Massey University. Proc. N.Z. Soc. Anim. Prod. 58:132-135.

McArt, J. A., D. V. Nydam, and M. W. Overton. 2015. Hyperketonemia in early lactation dairy cattle: A deterministic estimate of component and total costs per case. J. Dairy Sci. 98:2043-2054. 
Miekley, B., I. Traulsen, and J. Krieter. 2012. Detection of mastitis and lameness in dairy cows using wavelet analysis. Livest. Sci. 148:227-236

Mostert, P. F., E. A. M. Bokkers, C. E. van Middelaar, H. Hogeveen, and I. J. M. de Boer. 2018. Estimating the economic impact of subclinical ketosis in dairy cattle using a dynamic stochastic simulation model. Animal 12:145-154. https://doi.org/10.1017/ S1751731117001306.

O'Connell, J., F. A. Tøgersen, N. C. Friggens, P. Løvendahl, and S. Højsgaard. 2010. Combining cattle activity and progesterone measurements using hidden semi-Markov models. J. Agric. Biol. Environ. Stat. 16:1-16.

Østergaard, S., N. C. Friggens, and M. G. G. Chagunda. 2005. Technical and economic effects of an inline progesterone indicator in a dairy herd estimated by stochastic simulation. Theriogenology 64:819-843.

Pastell, M., J. Tiusanen, M. Hakojarvi, and L. Hanninen. 2009. A wireless accelerometer system with wavelet analysis for assessing lameness in cattle. Biosyst. Eng. 104:545-551.

Purvis, A., W. G. Boggess, C. B. Moss, and J. Holt. 1995. Technology adoption decisions under irreversibility and uncertainty-An ex ante appproach. Am. J. Agric. Econ. 77:541-551.

Raboisson, D., M. Mounie, and E. Maigne. 2014. Diseases, reproductive performance, and changes in milk production associated with subclinical ketosis in dairy cows: A meta-analysis and review. J. Dairy Sci. 97:7547-7563.

Roche, J. R., N. C. Friggens, J. K. Kay, M. W. Fisher, K. J. Stafford and D. P. Berry. 2009. Invited review: Body condition score and its association with dairy cow productivity, health, and welfare. J. Dairy Sci. 92:5769-5801.

Russell, R. A., and J. M. Bewley. 2013. Characterization of Kentucky dairy producer decision-making behavior. J. Dairy Sci. 96:47514758 .
Rutten, C. J., W. Steeneveld, C. Inchaisri, and H. Hogeveen. 2014. An ex ante analysis on the use of activity meters for automated estrus detection: To invest or not to invest? J. Dairy Sci. 97:6869-6887.

Rutten, C. J., W. Steeneveld, J. C. M. Vernooij, K. Huijps, M. Nielen, and H. Hogeveen. 2016. A prognostic model to predict the success of artificial insemination in dairy cows based on readily available data. J. Dairy Sci. 99:6764-6779.

Rutten, C. J., A. G. J. Velthuis, W. Steeneveld, and H. Hogeveen. 2013. Invited review: Sensors to support health management on dairy farms. J. Dairy Sci. 96:1928-1952.

Spoliansky, R., Y. Edan, Y. Parmet, and I. Halachmi. 2016. Development of automatic body condition scoring using a low-cost 3-dimensional Kinect camera. J. Dairy Sci. 99:7714-7725.

Steeneveld, W., and H. Hogeveen. 2012. Economic consequences of immediate or delayed insemination of a cow in oestrus. Vet. Rec. 171:17.

Steeneveld, W., and H. Hogeveen. 2015. Characterization of Dutch dairy farms using sensor systems for cow management. J. Dairy Sci. 98:709-717.

Tozer, P. R. 2009. Uncertainty and investment in precision agriculture-Is it worth the money? Agric. Syst. 100:80-87.

Trigeorgis, L., and J. J. Reuer. 2017. Real options theory in strategic management. Strateg. Manage. J. 38:42-63.

van der Drift, S. G. A., R. Jorritsma, J. T. Schonewille, H. M. Knijn, and J. A. Stegeman. 2012. Routine detection of hyperketonemia in dairy cows using Fourier transform infrared spectroscopy analysis of beta-hydroxybutyrate and acetone in milk in combination with test-day information. J. Dairy Sci. 95:4886-4898.

van Soest, F. J. S., I. M. G. A. Santman-Berends, T. J. G. M. Lam, and H. Hogeveen. 2016. Failure and preventive costs of mastitis on Dutch dairy farms. J. Dairy Sci. 99:8365-8374.

Wageningen Economic Research. 2016. Accessed Dec. 14, 2016 https://www.agrimatie.nl/agrimatieprijzen/default.aspx?Lang=0 